\title{
Cellulose nanocrystal extraction from rice straw using a chlorine-free bleaching process
}

\author{
Shih-Chen Shi - Guan-Ting Liu
}

Received: 14 May 2020/Accepted: 28 April 2021/Published online: 15 May 2021

(C) The Author(s), under exclusive licence to Springer Nature B.V. 2021

\begin{abstract}
Cellulose nanocrystals (CNCs) have attracted tremendous attention because of their excellent chemical and physical properties and due to their renewability and sustainability. This material can be extracted from agricultural by-products such as rice straw, banana tree, or bagasse. Rice straw was selected as the raw material in this study. Initially, a large amount of lignin must be removed by an alkaline process to obtain a slurry. Thereafter, a green bleaching process can be used to remove the remaining lignin in the slurry. An UV-emitting diode with $365 \mathrm{~nm}$ wavelength assisted the oxidation reaction of the $\mathrm{H}_{2} \mathrm{O}_{2}$ solution without the use of chlorine-containing chemical bleach. The reaction required only $2.5 \mathrm{~h}$ to obtain high-purity cellulose and successfully enhanced the yield. Transmission electron microscopy images showed that the CNCs from rice straw were $\sim 100$ $\mathrm{nm}$ long and 10-15 nm wide. The crystalline index and degradation temperature of CNCs were $83.8 \%$ and $257{ }^{\circ} \mathrm{C}$, respectively.
\end{abstract}

Keywords Bleaching process - Cellulose · Mechanism · Oxidation · UV

S.-C. Shi $(\varangle) \cdot$ G.-T. Liu

Department of Mechanical Engineering, National Cheng

Kung University (NCKU), Tainan, Taiwan

e-mail: scshi@mail.ncku.edu.tw

\section{Introduction}

Cellulose is one of the most important organic compounds on earth and is obtained from plants, algae, bursal animals, and bacteria. Cellulose structures and names are clearly classified according to different geometric sizes (Trache et al. 2017). Micronto nano-scale applications differ and are determined by the cellulose geometric size (Mariano et al. 2014). The basic unit of cellulose is a pair of glucose molecules which form units with $\beta$ - $(1 \rightarrow 4)$-glycosidic bonds. This unit repeats to form a cellulose linear molecular chain. Cellulose has six hydroxyl groups and three oxygen atoms on each unit; therefore, there are six hydrogen-bond donors and nine hydrogenbond acceptors available to form different intramolecular and intermolecular hydrogen bonding. These complex hydrogen bonding systems, coupled with van der Waals interactions, organize the cellulose chain into a semicrystalline polymer. These polymers entangle with each other, forming microfibril. Cellulose is composed of hemicellulose and micron cellulose which are formed through a biosynthetic mechanism, exhibit high strength and toughness, and are present in plant cell walls.

Studies on cellulose axial stiffness concluded that the average elastic modulus of cellulose was 132/92 $\mathrm{GPa}$, with and without consideration of hydrogen bonding, which greatly affects cellulose strength (Mariano et al. 2014). Using atomic force microscopy, 
three point bending tests were performed on cellulose, demonstrating that the elastic modulus of cellulose nanofibers and cellulose nanocrystals (CNCs) were $145.2 \pm 31.2$ and $150 \pm 28.8 \mathrm{GPa}$, respectively (Iwamoto et al. 2009). Additionally, CNC is nontoxic and has a low thermal expansion coefficient, easy surface chemical modification, and low density. CNC films have high transparency, reproducibility, and biodegradability, and, therefore, can be used as nanocomposite fillers and in drug delivery, textiles, panels, and filtration membranes (Zhu et al. 2016).

Removal of lignin by chemical or mechanical force is necessary before prior to the extraction of nanocellulose material from rice straw. Cellulose extracted in the paper industry is referred to as pulp. Mechanical pulping methods have a high pulp yield but a high lignin content, whereas chemical pulping has a lower lignin content but a lower yield (Davidsdottir 2013; Hintz and Lawal 2018). Using a multi-stage chemical pulping process provides pulp with a relatively high yield and low lignin residue (Trache et al. 2017). In each step, chemicals with different cellulose degradation degrees are selected, and the reaction steps are designed accordingly. Multistage processing is divided into two processes: First, large quantities of lignin are removed by sulfate or alkaline processes. Second, the cellulose yield is enhanced using bleach to remove residual lignin and improve the purity and brightness of cellulose. The traditional bleaching process uses a chlorine-containing chemical, such as sodium hypochlorite, which is accessible and inexpensive; however, purification of the waste liquid after extraction is difficult and can cause serious environmental pollution. Elemental Chlorine Free (ECF) and Total Chlorine Free (TCF) technologies were developed to replace chlorine as a bleaching agent due to environmental considerations. Chlorine dioxide is used in ECF, and in TCF, higher dosages of peroxide or ozone were added to compensate for the lack of chlorine oxide (Jour et al. 2013).

Peroxide is a convenient and versatile oxidant which is relatively stable when it is in a neutral aqueous solution at room temperature, has a low dissociation degree, and is a weak acid (Pędziwiatr 2018). At high temperatures, $\mathrm{H}_{2} \mathrm{O}_{2}$ is unstable and easily decomposes spontaneously, generating hydroxyl radicals $(\mathrm{OH})$ (Sun et al. 2000). $\mathrm{H}_{2} \mathrm{O}_{2}$ in solution absorbs a large range of near-ultraviolet (UV) radiation $(375-215 \mathrm{~nm})$, and a red shift occurs as the solution $\mathrm{pH}$ increases. $\mathrm{H}_{2} \mathrm{O}_{2}$ decomposes into $\mathrm{HOO}^{-}$ and $\mathrm{H}^{+}$(Muhammad and Rao 1957). It has a limited redox potential in the reaction with lignin, which has a relatively stable structure. The mechanism of lignin decomposition by $\mathrm{H}_{2} \mathrm{O}_{2}$ has been proposed and discussed, proving that the free radicals generated by $\mathrm{H}_{2} \mathrm{O}_{2}$ in alkaline solutions are the main substances that destroy the structure of lignin (Gould 1985). When the solution is alkaline (the optimal $\mathrm{pH}$ is 11.5), a large amount of hydroperoxy radicals $\left(\mathrm{HO}_{2}{ }^{-}\right)$are released, generating more hydroxyl radicals $\left(\mathrm{OH}^{-}\right)$. The hydroperoxy radical is a nucleophilic reagent. Its main function is to perform a redox reaction with the colored groups of lignin to improve the brightness of the slurry. The hydroxyl radical is an electrophile reagent with an extremely high redox potential and can decompose the lignin structure. It also improves the whiteness of the slurry and increases the degree of purification.

The hydroxyl radical has no reaction selectivity; therefore, it also reacts with cellulose, resulting in a reduced cellulose yield, which should be avoided in the pulping process. However, the degree of purification is critical for nanocellulose extraction, therefore, more free radicals in the $\mathrm{H}_{2} \mathrm{O}_{2}$ solution need to be generated. Some studies extracted cellulose from agricultural waste such as rye straw (Sun et al. 2000) and rice straw (Sun et al. 2001) by using $\mathrm{H}_{2} \mathrm{O}_{2}$; however, the process took more than $12 \mathrm{~h}$.

The use of advanced oxidation processes or metaloxide nanoparticle photocatalytic reactions, such as the Fenton reaction, $\mathrm{TiO}_{2} / \mathrm{hv} / \mathrm{O}_{2}, \mathrm{O}_{3} / \mathrm{UV}$ and $\mathrm{H}_{2} \mathrm{O}_{2} /$ $\mathrm{UV}$, can also generate hydroxyl radicals. These methods use direct or indirect reactions to generate high oxidizing free radicals and are usually used in wastewater purification to treat recalcitrant chemicals. The $\mathrm{H}_{2} \mathrm{O}_{2} / \mathrm{UV}$ process is undertaken by irradiating $\mathrm{H}_{2} \mathrm{O}_{2}$ with a UV light source at $254 \mathrm{~nm}$, forcing it to undergo a homolytic reaction and generating a large number of hydroxyl radicals. Although this method has an excellent oxidizing ability, the light source in this band is free radiation, which damages living organisms.

Studies on metal oxide photocatalysts have also become popular and have applications in sewage treatment, sterilization, and air purification. According to the free radical generation principle, the photocatalyst material is irradiated with a light source causing the electrons gain energy and excite from the valence 
band to the conduction band, forming an electron-hole pair. The high activity electron-hole pairs convert oxygen or water molecules into active oxygen species or free radicals with high oxidation abilities. Many metal oxide nanoparticles can be used as photocatalysts, such as $\mathrm{ZnO}, \mathrm{TiO}_{2}, \mathrm{SnO}_{2}$, and $\mathrm{CdS}$, among which $\mathrm{TiO}_{2}$ is widely used due to its excellent chemical stability. Natural $\mathrm{TiO}_{2}$ has three crystal structures, namely anatase, rutile, and rookite. Anatase and rutile have photocatalyst abilities with band gaps of 3.0 and $3.2 \mathrm{eV}$, respectively. According to the Planck-Einstein formula, anatase $(387.5 \mathrm{~nm})$ requires a light source with a lower wavelength than rutile $(413 \mathrm{~nm})$ for excitation. Therefore, when an electronhole pair is formed, anatase produces a strong redox capacity. The difficulty in practical application is that when an electron-hole pair is generated, an excited electron easily returns to the ground state, referred to as the recombination effect, which greatly reduces free radical generation and affects the decontamination efficiency. Hirakawa et al. used a fluorescent probe to study the effect of $\mathrm{H}_{2} \mathrm{O}_{2}$ in a $\mathrm{P} 25$-type $\mathrm{TiO}_{2}(20 \%$ rutile and $80 \%$ anatase), and proposed that an appropriate amount of $\mathrm{H}_{2} \mathrm{O}_{2}$ can be adsorbed on the surface of $\mathrm{TiO}_{2}$ (Hirakawa and Nosaka 2002). Since the oxidation-reduction potential of $\mathrm{H}_{2} \mathrm{O}_{2}$ is lower than that of photo-holes, $\mathrm{H}_{2} \mathrm{O}_{2}$ reacts with holes to decelerate the decay of superoxide $\left(\mathrm{O}_{2}{ }^{-}\right)$, reducing the recombination possibility. Adsorbed $\mathrm{H}_{2} \mathrm{O}_{2}$ also generates a photo-Fenton reaction with conduction band electrons, accelerating hydroxyl radical generation (Hirakawa and Nosaka 2002). Boonstra and Mutsaers (1975) proposed that $\mathrm{H}_{2} \mathrm{O}_{2}$ is easily adsorbed on the surface of $\mathrm{TiO}_{2}$ and that rutile adsorbs more than anatase under the same conditions. Hirakawa and Nosaka (2002) proposed that the photocatalyst reaction mechanisms of rutile and anatase are different. Without $\mathrm{H}_{2} \mathrm{O}_{2}$, only anatase can generate hydroxyl radicals, and with $\mathrm{H}_{2} \mathrm{O}_{2}$, the ability of anatase to generate hydroxide radicals decreases with the addition of $\mathrm{H}_{2} \mathrm{O}_{2}$. Inversely, $\mathrm{H}_{2} \mathrm{O}_{2}$ adsorbed on the surface of rutile consistently increases the production of hydroxide radicals (Hirakawa et al. 2007).

Research on the application of cellulose materials has gradually increased (Zhu et al. 2016), especially in the field of green electronics (Bao et al. 2014; Fujisaki et al. 2014; Yang et al. 2011), biological devices (Dungchai et al. 2011; Pourreza et al. 2015; Tian et al. 2012), energy fields (Sun et al. 2020; Yabuuchi et al.
2014; Yu et al. 2013), and wear protection applications (Shi and Jiang 2020; Shi and Pek 2019; Shi and Peng 2020; Shi et al. 2018). Therefore, the development of high-efficiency, high-purity, and high-brightness CNC processes is important for the future applications.

In this study, rice straw was selected as the raw material because of the ease of accessibility, locally high yield, sustainability, and recyclability. In Taiwan, rice cultivation accounts for more than one-third of all arable land, and is the most important agricultural products. Furthermore, rice straws are traditionally burned post-harvest. In 2000, burning was prohibited to prevent air pollution, and farmers have since faced problems in managing agricultural waste. Creating new demand for agricultural waste not only solves the disposal problem but also introduces economic benefits. Prior to extracting nanocellulose from agricultural waste, structures other than cellulose must be removed. To prevent environmental pollution, this study used $\mathrm{H}_{2} \mathrm{O}_{2}$ for the bleaching process, and UV lightings and $\mathrm{TiO}_{2}$ photocatalyst reactions were used to improve bleaching efficiency (BE).

\section{Experimental}

\section{Materials}

Rice straw was initially crushed into a fine powder and sieved with a no. $18 \mathrm{Mesh}$. The ash content of the rice straw was determined in accordance with ISO 1762:2001. The silicon content in ash was measured using energy-dispersive X-ray spectroscopy (EDS). After refinement of the straw material, a Soxhlet extractor was used to remove and dry the oil. Subsequently, an $\mathrm{NaOH}$ solution was used to treat the raw materials, referred to as the alkaline process (Law et al. 2001; Oluwasina et al. 2014; Puls et al. 2006). After the alkaline process, small amounts of residual lignin remained in the slurry. Thereafter, a bleaching process was used to extract the cellulose materials with high purity and whiteness. In this step, peroxide was used as a bleaching reagent instead of chlorine dioxide. Because the efficiency of bleaching process with peroxide was limited, we used a UVassisted $\mathrm{TiO}_{2}$ photocatalyst reaction to improve the efficiency. 
Alkaline procedure

Aqueous sodium hydroxide, at specific concentrations of $1,2,3,4$, and $5 \mathrm{wt} \%$, was prepared as the reaction solution. The weight ratio of the reaction solution to raw material was 20:1. The alkaline process was conducted at $90 \pm 2{ }^{\circ} \mathrm{C}$ and $300 \mathrm{rpm}$, and allowed a 2-h reaction time.

Chlorine-free bleaching sequence

A peroxide solution, at specific concentrations of 1,2, 3 , and $4 \mathrm{wt} \%$, was prepared as the bleaching solution. The weight ratio of the bleaching solution to slurry after alkaline process was 30:1. The chlorine free bleaching process was carried out at $80 \pm 2{ }^{\circ} \mathrm{C}$ and $200 \mathrm{rpm}$, and allowed a 1.5 -h reaction time. The UV light wavelength was $365 \mathrm{~nm}$, and the total irradiation energy was $57.6 \mathrm{~W}$. Experiments were divided into three groups, namely the control, UV, and $\mathrm{UV} / \mathrm{TiO}_{2}$ groups.

Pulp number and pulp analysis

The Kappa number test was determined in accordance with ISO 302:2204, and aims to determine the degree of delignification of pulp. After the reaction under different conditions, the residual lignin in the slurry was measured. The Kappa number, lignin content, total yield, and BE were calculated as per Eqs. (1)-(4).

$$
\begin{aligned}
\text { Kappa Number }= & \mathrm{N} \times(\mathrm{B}-\mathrm{A}) \times(11.073 \mathrm{~B} \\
& -2.14 \mathrm{~A})(1.325-0.013 \mathrm{~T}) /(\mathrm{W} \\
& \times \mathrm{B})
\end{aligned}
$$

Here, $\mathrm{N}$ is the equivalent concentration of $\mathrm{Na}_{2} \mathrm{~S}_{2} \mathrm{O}_{3}$; $\mathrm{B}$ is the titration volume of the blank experiment; $\mathrm{A}$ is the titration volume of slurry; $\mathrm{W}$ is the dry weight of slurry; and $\mathrm{T}$ is temperature.

Residual lignin content was determined using the following equation.

Lignin content $(\%)=$ Kappa Number $\times 0.15$

Total yield was calculated by Eq. (3).

Total yield $=\frac{\text { Cellulose weight after alkaline process }}{\text { Cellulose weight before alkaline process }}$
Bleaching efficiency (BE) was determined by Eq. (4).

$(B E)=\frac{\text { Lignin content of cellulose after (alkaline process - bleaching process) }}{\text { Lignin content of cellulose after alkaline process }}$

Handsheet formation for the physical test was performed according to ATPPI T 205 om-88. Pulp brightness was measured in accordance with TAPPI T 452. All measurements were replicated to obtain reproducible data.

\section{Preparation of CNCs}

The slurry obtained after the alkaline process and chlorine-free bleaching sequence was mixed with $11-\mathrm{M} \mathrm{H}_{2} \mathrm{SO}_{4}$ at $25{ }^{\circ} \mathrm{C}$ for $30 \mathrm{~min}$. A centrifuge was used to filter and wash the suspension, after which it was dialyzed. A $1200-\mathrm{W}$ sonication treatment was carried out for $30 \mathrm{~min}$, after which the slurry was vacuum filtered and placed in a freeze dryer to prepare the CNC powder.

\section{Analysis of CNC}

Geometric morphology of CNS was collected using a high-resolution field emission gun-transmission electron microscopy (HRFE-TEM, SU-500, HITACHI, Japan). Crystallization parameters were collected by a Bruker diffractometer, Model D2 phaser, using CuK $\alpha$ $(\mathrm{K} \alpha 1,0.15406 \mathrm{~nm})$ at an operating voltage and current of $30 \mathrm{kV}$ and $10 \mathrm{~mA}$, respectively. The blank scan is carried out using a clean zero background plate with no applied sample. The blank scan will be subtracted during the analysis. Attenuated total reflection Fourier-transform infrared (ATR-FTIR) spectra of the materials were recorded by a FTIR Spectrometer (Nicolet iS5, ThermoFisher Scientific, USA). All the FTIR samples were crushed into small particles, combined with $\mathrm{KBr}$, and pressed into a small disc. Thermo- gravimetric analysis (TGA) were carried out using a simultaneous thermal analyzer (STA, 449 F3 Jupiter, NETZSCH, Germany). The contents of the sulfur functional groups of CNCs were determined using an organic elemental analyzer (UNICUBE, Elementar Analysensysteme GmbH, Langenselbold, Germany). Three tests were performed under each of the experimental conditions. 


\section{Results and discussion}

Ash and silicon content of rice straw

Rice straws are a residue produced in large quantities worldwide. While this material is utilized in some areas, in other areas it is considered a waste product, causing pollution and disposal problems. Highly pozzolanic ash and high silicon content cause difficulties in the subsequent treatment of pulping wastewater (Chen et al. 2018). Rice straw produced approximately $15 \%$ ash after burning; thus, $15 \mathrm{~kg}$ ash were produced from every $100 \mathrm{~kg}$ of rice straw burnt, with a silicon content of approximately $33 \%$.

Kappa test of alkaline process slurry

The alkaline process rapidly removed large amounts of lignin. The residual lignin in the slurry was not significantly decreased with increasing concentrations of $\mathrm{NaOH}$, as depicted in Fig. 1. However, the total slurry yield significantly decreased with increasing $\mathrm{NaOH}$ concentrations. This means that a high $\mathrm{NaOH}$ concentration affects the structure of plant cells.

The BE calculated in the Kappa test represents the effect of the bleaching method on residual lignin removal after the alkaline process. A high $\mathrm{BE}$ value indicates small amounts of residual lignin. Figure 2 shows that when the concentration of the $\mathrm{H}_{2} \mathrm{O}_{2}$ solution was fixed, the reaction solution $\mathrm{BE}$ was affected by temperature. At $20{ }^{\circ} \mathrm{C}$, the ability of $\mathrm{H}_{2} \mathrm{O}_{2}$ to oxidize lignin was quite limited, mainly because $\mathrm{H}_{2} \mathrm{O}_{2}$ is stable at low temperatures, and the redox potential of $\mathrm{H}_{2} \mathrm{O}_{2}$ is not high, which resulted in the low efficiency of the three bleaching methods at low temperature. However, in a high-temperature environment, $\mathrm{H}_{2} \mathrm{O}_{2}$ will partially undergo a homolytic reaction to generate hydroxyl radicals which have high oxidation-reduction potentials and enhance the BE. Therefore, the following experiments were performed at high temperatures. Additionally, the BE improved greatly after $\mathrm{UV}$-assisted $\mathrm{TiO}_{2}$ photocatalyst reactions at high and low temperatures.

Figure 3 shows that the $\mathrm{BE}$ was directly proportional to the $\mathrm{H}_{2} \mathrm{O}_{2}$ concentration. With UV light irradiation and $\mathrm{UV}$-assisted $\mathrm{TiO}_{2}$ photocatalyst reaction, the BE was $200 \%$ more than that of the control group. The $\mathrm{BE}$ of the $\mathrm{TiO}_{2}$ photocatalyst-assisted group was slightly lower than that of the UV-assisted

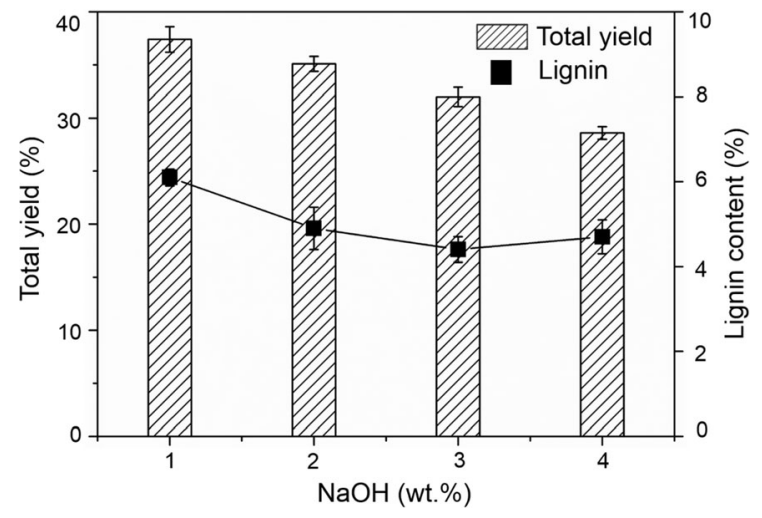

Fig. 1 Slurry Kappa test results after the alkaline process at different $\mathrm{NaOH}$ concentrations

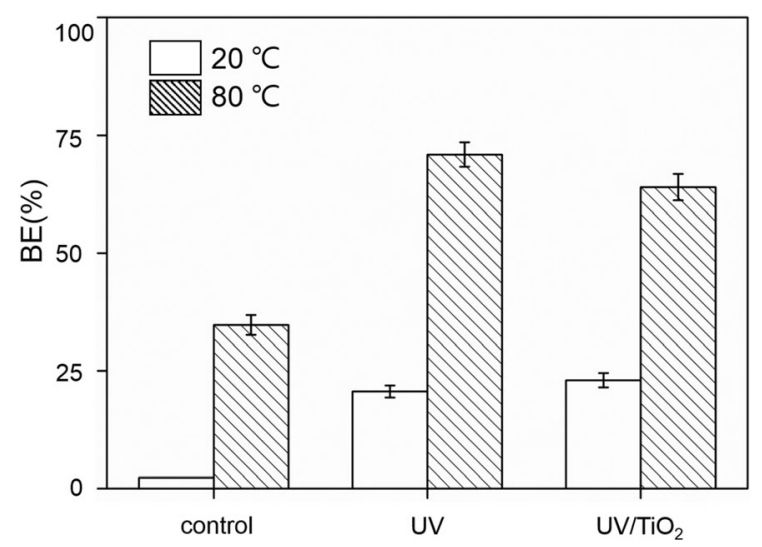

Fig. 2 Relationship between temperature and BE

group, and the $\mathrm{BE}$ decreased with increasing $\mathrm{TiO}_{2}$ additions.

In the control group, an electromagnetic heating stirrer was used as the heat source to rapidly heat the solution to $80 \pm 2{ }^{\circ} \mathrm{C}$ within $5 \mathrm{~min}$, and then maintain it at a constant temperature. The control group produced more hydroxyl radical to destroy lignin in a short period of time. Therefore, the bleaching effect of the control group was stronger than that of the UVassisted group within $20 \mathrm{~min}$; however, the bleaching effect of the control group remained identical after 20 min, as shown in Fig. 4.

For the UV-assisted group, a UV light source was used as the heat source, and the temperature reached $80 \pm 2{ }^{\circ} \mathrm{C}$ after $30 \mathrm{~min}$ irradiation, and then a constant temperature was maintained. Therefore, limited hydroxyl radicals were generated in the first $30 \mathrm{~min}$, resulting in poor lignin removal capacity, 


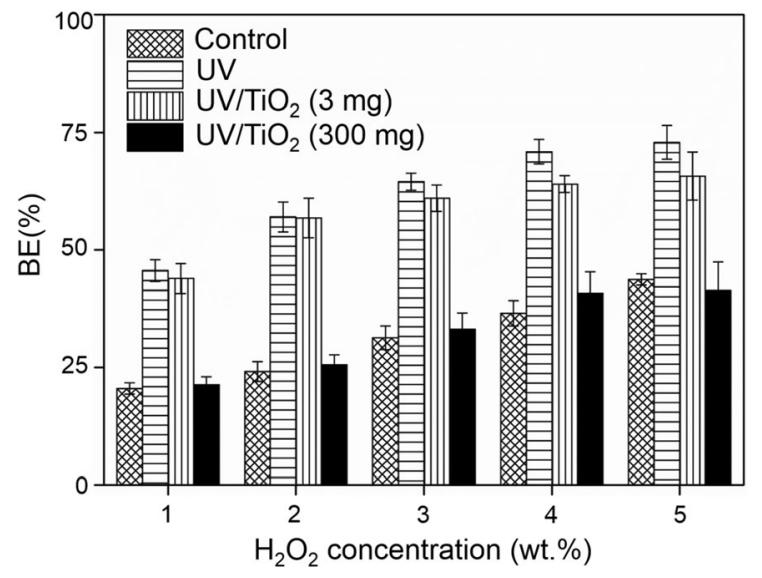

Fig. 3 BE comparison of the different bleaching methods

which was consistent with the results in Fig. 2 for the low-temperature conditions. Additionally, the removed lignin content increased proportionally with time after UV irradiation, and UV irradiation greatly improved the $\mathrm{H}_{2} \mathrm{O}_{2}$ bleaching ability.

\section{Mechanism for UV-assisted bleaching efficiency}

It is reported that UV light irradiation performed a photodegradation reaction with some of the lignin functional groups, however, the reaction was very slow and it usually took up to 10 days for a significant change (Hon and Chang 1984). This experimental UV irradiation rapidly removed large amounts of lignin in less time. The direct interaction between $\mathrm{UV}$ and $\mathrm{H}_{2} \mathrm{O}_{2}$ produced an excess of hydroxyl radicals, and the possibility of a large increase in BE was also excluded because the UV wavelength must be below $254 \mathrm{~nm}$. When the $\mathrm{H}_{2} \mathrm{O}_{2}$ solution reacts with lignin, the residual non-phenolic lignin in slurry decomposes into phenolic lignin, which, with different functional groups, has different antioxidant effects on oxidants (Dizhbite et al. 2004). Therefore, it was confirmed that phenolic lignin can resist oxidation, which significantly reduces the oxidation reaction rate. $\mathrm{A}_{2} \mathrm{O}_{2}$ solution at high temperature generated hydroxyl radicals which destroyed residual non-phenolic lignin, however, the phenolic lignin anti-oxidation ability was also simultaneously generated in the solution. Antioxidant substances severely reduced the hydroxyl radical oxidizing ability. This result is depicted in the $\mathrm{H}_{2} \mathrm{O}_{2}$ group BE result in Fig. 4.

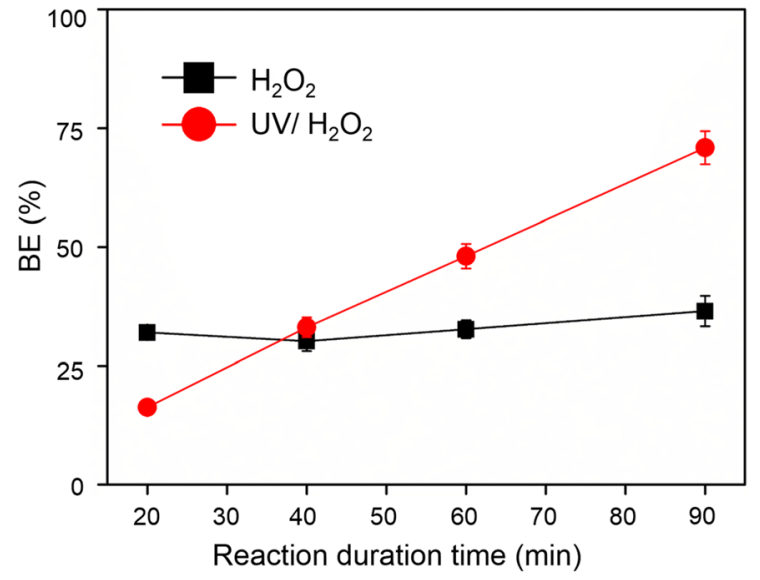

Fig. 4 Relationship between UV light irradiation and BE (4 wt $\% \mathrm{H}_{2} \mathrm{O}_{2}, 80{ }^{\circ} \mathrm{C}$ )

Phenolic lignin reacts with peroxide and UV to generate phenoxyl radicals, and is then converted into an unstable quinone structure and finally decomposes into aliphatic acids by a photo-oxidation reaction (Wang et al. 2016). It was determined that in the peroxide solution, the UV light had sufficient energy to convert the functional group in the phenolic lignin. The antioxidant behavior of phenolic lignin was depressed by the UV light and partly transformed into a component lacking antioxidant behavior. The antioxidant ability of the overall solution was depressed. The hydroxyl radical chain reaction occurred, thus greatly improving the $\mathrm{BE}$.

$\mathrm{H}_{2} \mathrm{O}_{2}$ stably reacts with rutile $\mathrm{TiO}_{2}$, and two types of hydroxyl radicals are generated, namely a free radical and an adsorbed radical on the surface of $\mathrm{TiO}_{2}$ which has a poor oxidizing ability. Besides, $\mathrm{TiO}_{2}$ absorbed and weakened the energy of the irradiated UV light. Therefore, the UV-assisted BE was superior to the $\mathrm{UV} / \mathrm{TiO}_{2}$ assisted process. Moreover, excessive amounts of $\mathrm{TiO}_{2}$ blocked and absorbed the light source, resulting in a significant reduction of the $\mathrm{BE}$ (Hirakawa et al. 2007).

\section{Bleaching performance}

Lignin is the main component of rice straw that is colored; therefore, the difference in BE between the control and UV-assisted group is reflected in the slurry color difference. Under the same reaction time and temperature, the bleaching method of the UV-assisted method improved the cellulose whiteness, as depicted 
in Fig. 5c, d. Combined with the Kappa test results, the increased whiteness was mainly because the UVassisted reaction removed more residual lignin in the slurry.

Structural change after process

Field emission-scanning electron microscopy (FESEM) aided in observing the changes in the straw surface structure after the alkaline process and chlorine-free bleaching sequence. The surface of the untreated rice straw exhibited fibers coated with lignin (Fig. 6a). After the alkaline treatment, fibers with a diameter of approximately $10 \mu \mathrm{m}$ were observed (Fig. 6b). After the chlorine-free bleaching sequence, part of the cellulose was further dismantled, reducing the fiber diameter to approximately $3 \mu \mathrm{m}$, and a finer fiber could be seen from inside the fiber (Fig. 6c). When a small amount of $\mathrm{TiO}_{2}$ was added $(3 \mathrm{mg})$, no nano- $\mathrm{TiO}_{2}$ was observed on the fiber. However, when excess $\mathrm{TiO}_{2}$ was added $\left(300 \mathrm{mg}\right.$ ), nano- $\mathrm{TiO}_{2}$ was adsorbed and was visible on the fiber surface, which affected the subsequent cellulose nanometerization (Fig. 6d).

\section{CNC analysis}

Figure 7 depicts the post-treatment state of the suspension. After hydrolyzation by $\mathrm{H}_{2} \mathrm{SO}_{4}, \mathrm{CNCs}$ exhibited transparency after dilution. Concurrently, due to thermal effects, CNCs exhibited an irregular

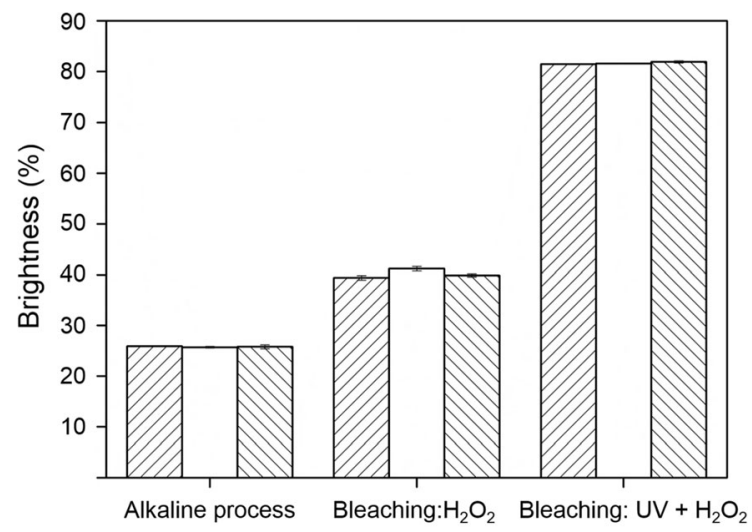

Fig. 5 Change in brightness of rice straw pulps during each pulping stage (note: the alkaline process was performed in an environment of $2 \mathrm{wt} \%$ sodium hydroxide; the bleaching process was performed in a solution of $4 \mathrm{wt} \%$ peroxide)
Brownian motion in the solution. The surface of CNCs prepared by the $\mathrm{H}_{2} \mathrm{SO}_{4}$ method contained sulfate ester functional groups, which negatively charged the surface of the particles. An electric double layer was formed on the surface of the particles, which generated an electrostatic repulsion force to overcome the attraction between the nanoparticles resulting from the insufficient coordination of numerous atoms and hydrogen bonding on the surface. However, the repulsive force of the electric double layer was greatly affected by the ionic strength in the solution. The asprepared suspension after dilution caused the CNCs to flocculate due to the high concentrations of $\mathrm{SO}_{4}{ }^{2-}$ and $\mathrm{H}^{+}$. After the dialysis, the ion concentration in the suspension gradually decreased. Simultaneously, a 1200-W ultrasonic processer dispersed the flocculated CNCs. The CNC surface formed a stable electric double layer and provided sufficient electrostatic repulsion between $\mathrm{CNCs}$, resulting in good dispersion of CNCs in the solution.

Figure 8 depicts the geometry of CNCs observed by TEM. The CNCs extracted from rice straw were approximately $100 \mathrm{~nm}$ long and 10-15 nm wide.

Figure 9 shows the X-ray diffraction (XRD) analysis of nanocellulose. The peak at 22.5 represents the distance of the 2D plane in the 3D stack, which is tightly combined with van der Waals force. Each 2D plane is formed by the combination of cellulose molecules through intermolecular and intramolecular hydrogen bonds. The complex hydrogen bonding system combined with van der Waals force interaction organized the cellulose chains into semi-crystalline polymers. Even in the untreated rice straw, although only a broad crystalline front is seen, the crystalline structure of cellulose I can be observed. The (200) peak is very broad and the (1-10)/(110) overlapped peak is still visible. The overlapping peak has two peaks, and it is proved by fitting the two peaks of cellulose near 16.5 degrees, which represent (1-10) and (110) of the two lattice constants (French 2014). French emphasized that using the crystallinity index method to calculate crystallinity is more suitable for similar instruments, sample preparation, and environment (French and Santiago Cintrón 2013). In the nanometerization process of cellulose by $\mathrm{H}_{2} \mathrm{SO}_{4}$ hydrolysis, the loose chemical structure is susceptible to being protonated with acid ions $\left(\mathrm{H}^{+}\right)$to cause a selective reaction. It removes non-crystalline 

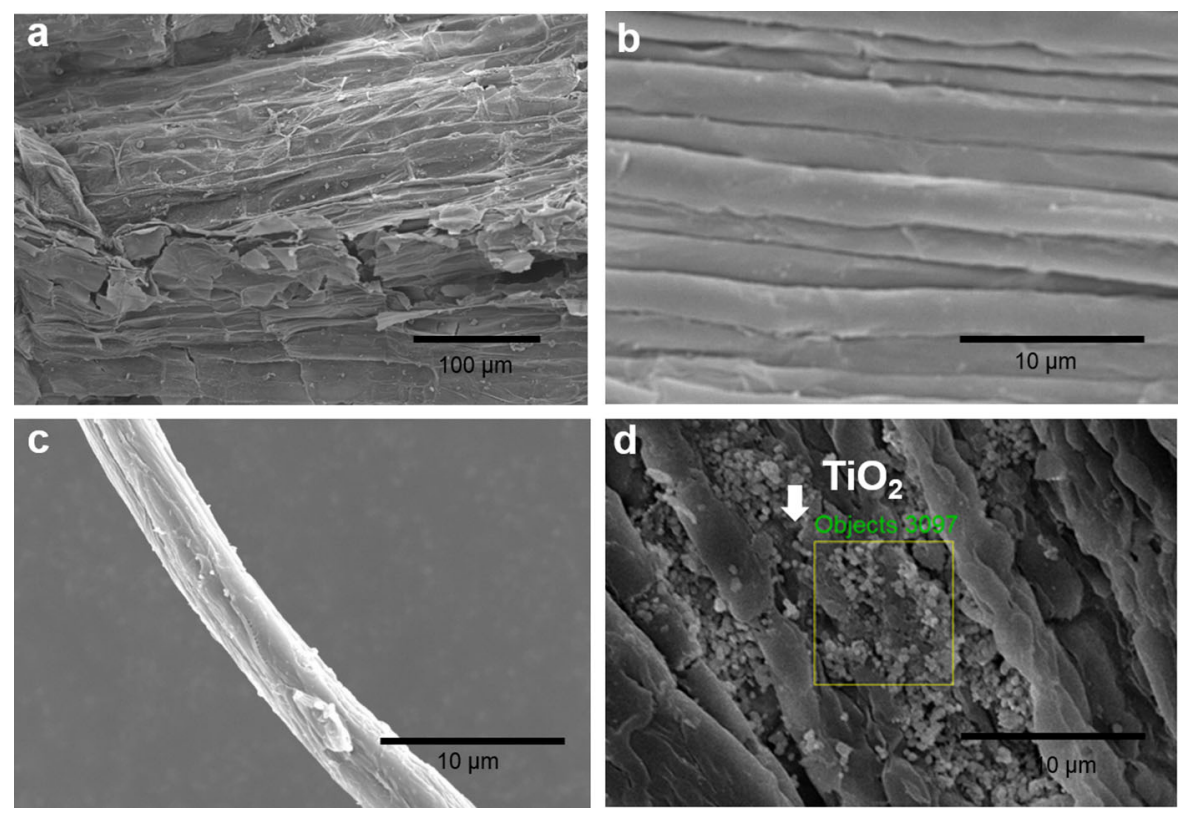

Fig. 6 FE-SEM images of the slurry surface: a rice straw before treatment; $\mathbf{b}$ fibers after the alkaline process with $2 \mathrm{wt} \% \mathrm{NaOH}$; $\mathbf{c}$ after the alkaline process and chlorine-free bleaching with $4 \mathrm{wt} \% \mathrm{H}_{2} \mathrm{O}_{2}$; and $\mathbf{d}$ residual $\mathrm{TiO}_{2}$

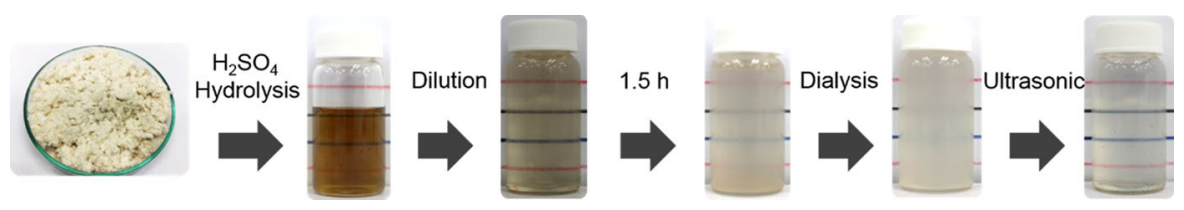

Fig. 7 Process of $\mathrm{H}_{2} \mathrm{SO}_{4}$ extraction of cellulose nanocrystals (CNCs)
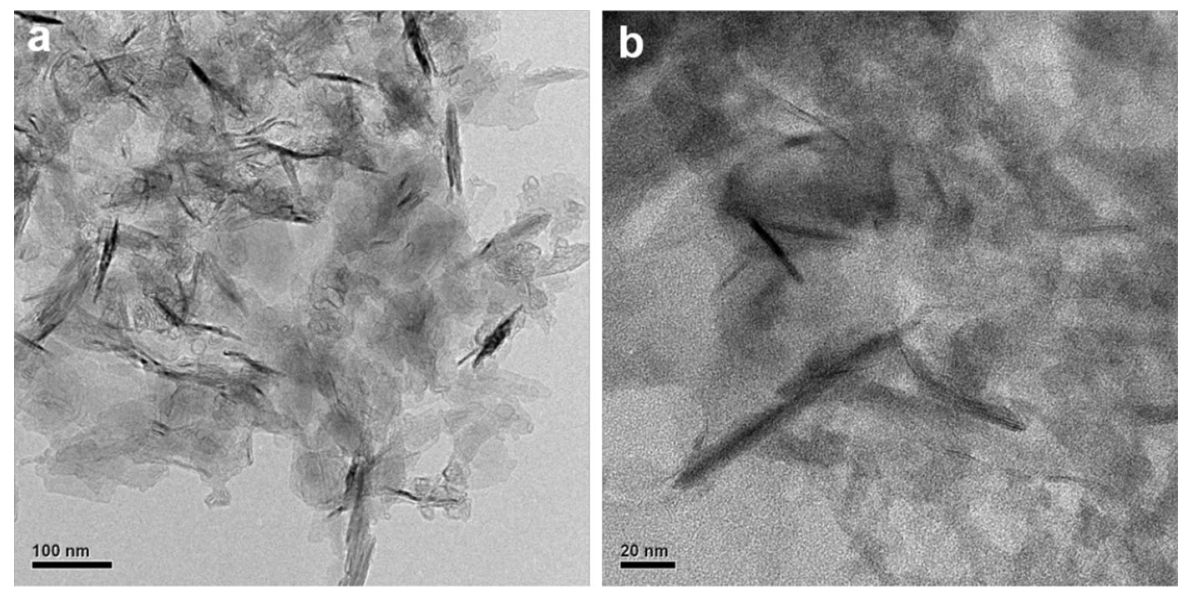

Fig. 8 Transmission electron microscopy (TEM) images of cellulose nanocrystals (CNCs): a low magnification; $\mathbf{b}$ high magnification

segments and lignin of the cellulose simultaneously, thereby leaving $\mathrm{CNCs}$ in the crystalline segment.
The two characteristic peaks at 2850 and $2920 \mathrm{~cm}^{-1}$ represent the wax component on the rice straw surface, respectively, as shown in Fig. 10. After 


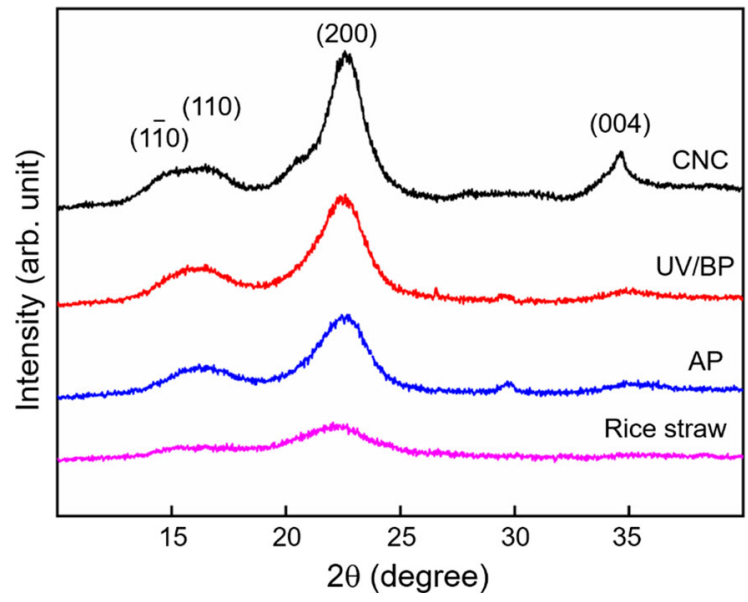

Fig. 9 XRD pattern of cellulose in different process stages

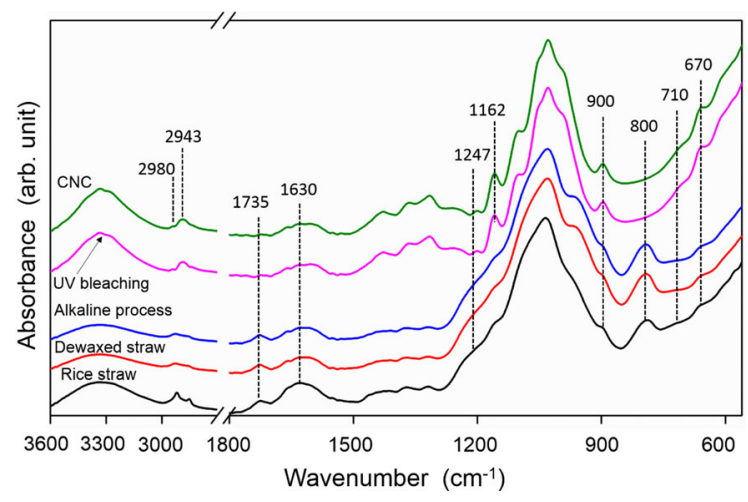

Fig. 10 Fourier Transform Infrared (FTIR) spectroscopy absorption spectrum of the slurry from each step. CNCcellulose nanocrystal

the toluene-ethanol mixed solution dewaxing treatment, the intensity of the two characteristic peaks reduced significantly. After the alkaline process, the chemical structure of the cellulose surface remained similar to that of the dewaxed rice straw. This means that ample lignin remained on the surface of the cellulose after the alkaline process. After the chlorinefree bleaching sequence, the characteristic peaks of cellulose material and rice straw were different. A broad characteristic peak $\left(3000-3500 \mathrm{~cm}^{-1}\right)$ represents a hydroxyl functional group. This peak became narrower and stronger due to the gradual exposure of cellulose to the surface after the chlorine-free bleaching process. Similarly, the characteristic peaks of 2980 and $2943 \mathrm{~cm}^{-1}$, representing the methylene symmetry and non-symmetry stretching vibration modes, respectively, were enhanced (Hinterstoisser et al. 2001;
Kumar et al. 2014). Two peaks, representing hemicellulose $\left(1735 \mathrm{~cm}^{-1}\right)$ and lignin benzene rings $\left(1630 \mathrm{~cm}^{-1}\right)$, decreased after the chlorine-free bleaching sequence (Hinterstoisser et al. 2001). The FTIR fingerprint clearly shows the obvious changes in the cellulose surface chemical structure after the different processes. The intensity of the three characteristic peaks, namely residual $\mathrm{SiO}_{2}$ on the rice straw $\left(800 \mathrm{~cm}^{-1}\right)$, carbonyl group of lignin $\left(1247 \mathrm{~cm}^{-1}\right)$, and the vibration of ether boning on aromatic ring $\left(1140 \mathrm{~cm}^{-1}\right.$ ), were significantly decreased (Derkacheva and Sukhov 2008; Hinterstoisser et al. 2001). The characteristic peaks representing the celluloses were $670,710,900,1054,1105,1162,1315$, and $1375 \mathrm{~cm}^{-1}$, and their intensities increased significantly. The important characteristic peaks at 710, 900, and $1162 \mathrm{~cm}^{-1}$ indicated the cellulose structure of monoclinic system (I $\beta$ ), non-crystalline cellulose, and $\beta$-(1-4) linkages, respectively (Park et al. 2010; Sugiyama et al. 1991). The signal of the CNCs extracted by the $\mathrm{H}_{2} \mathrm{SO}_{4}$ method became smooth, and all the characteristic peaks, except cellulose, completely disappeared. This means that the purity of the CNCs extracted by the $\mathrm{H}_{2} \mathrm{SO}_{4}$ method was rather high. Additionally, the characteristic peak at $1205 \mathrm{~cm}^{-1}$ indicated that the sulfate ester function groups substituted part of the hydroxyl group on the cellulose surface.

Since the degree of substitution of the sulfate halfester functional group severely affects the thermal degradation temperature of CNCs, an element analyzer measured the sulfur element content. The sulfur element ratio was proportional to the degree of substitution of the sulfate half-ester functional group. The results are detailed in Table 1. After the treatment of cellulose with $\mathrm{H}_{2} \mathrm{SO}_{4}$ hydrolysis, the average sulfur content increased to $2.36 \%$.

The two samples were not dried prior to the test, causing moisture adsorption on the surface and resulting in partial weight loss of cellulose and CNCs at $35-150{ }^{\circ} \mathrm{C}$. Due to the higher amount of water adsorbed by CNCs, the weight loss was more severe (Fig. 11a). The thermal degradation temperature of cellulose was $366^{\circ} \mathrm{C}$, and the weight dropped to $15 \%$ in the $280-390{ }^{\circ} \mathrm{C}$ range, which proves that the purity of UV-assisted cellulose extraction was rather high. The slope at high temperature was due to the presence of the sulfate half-ester functional groups on the CNC surface. The thermal degradation temperature of 
Table 1 Element contents of cellulose and cellulose nanocrystals (CNCs) (expressed as elemental by weight content) measured by elemental analysis

\begin{tabular}{llllll}
\hline Sample & Sample weight $(\mathrm{mg})$ & $\mathrm{N}(\%)$ & $\mathrm{C}(\%)$ & $\mathrm{H}(\%)$ & $\mathrm{S}(\%)$ \\
\hline Cellulose & 2.520 & 0.00 & 40.29 & 7.24 & 0.08 \\
& 2.805 & 0.01 & 40.37 & 3.41 & 0.03 \\
CNCs & 2.764 & 0.17 & 31.98 & 6.40 & 6.29 \\
& 2.577 & 0.18 & 2.28 & 2.44 \\
\hline
\end{tabular}

Fig. 11 a Thermogravimetric analysis (TGA) analysis, and $\mathbf{b}$ thermal degradation temperature of cellulose (UV-assisted chlorine-free bleaching sequence) and cellulose nanocrystal (CNC)

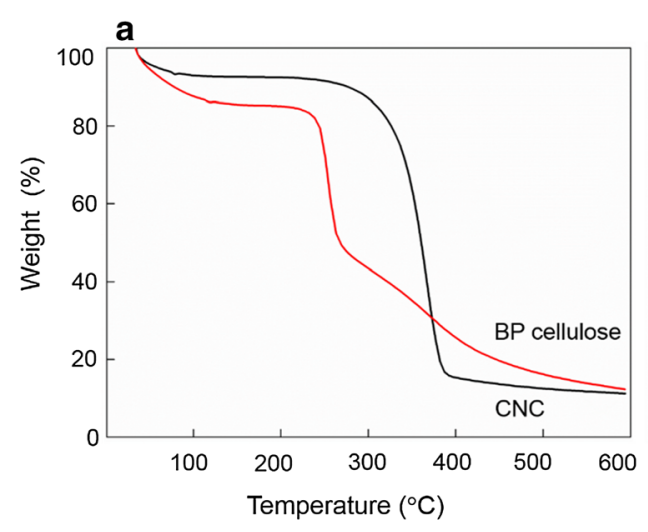

b

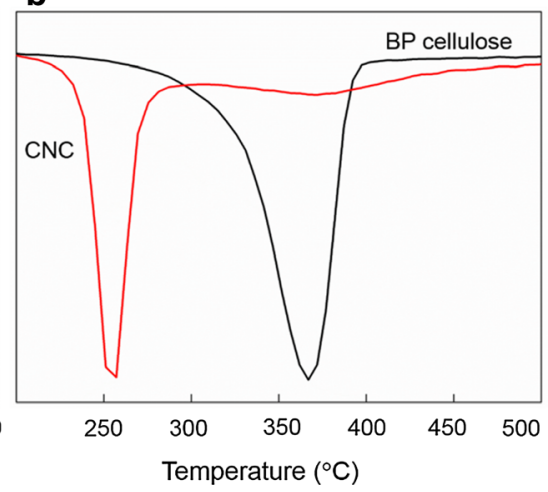

CNCs was $257^{\circ} \mathrm{C}$ (Fig. 11b). The $\mathrm{CNCs}$ sulfur content in this experiment was much higher than that reported by Lin and Dufresne (2014), however, a higher thermal degradation temperature was obtained. The high sulfur concentration was due to the sulfonate group that remains on the CNC surface after $\mathrm{H}_{2} \mathrm{SO}_{4}$ hydrolysis, which assists in subsequent dispersion and storage.

\section{Conclusion}

The aim of the work was to develop a chlorine-free bleaching method for the extraction of cellulose nanocrystal from rice straw. The total yield and residual lignin were determined. The $\mathrm{BE}$ increased by 200\% during the UV-assisted peroxide bleaching process. The mechanism of UV irradiation was to depress the antioxidant behavior of phenolic lignin. A CNC with a 10-20-nm diameter and high aspect ratio was obtained by this process. XRD, FTIR, elemental analysis, and TGA clearly support the isolation of CNCs. It can be concluded that by adopting the chlorine-free bleaching process, cellulose can be easily bleached from raw material with high efficiency and using environmentally friendly reagents. For the cost-effective production of cellulose nanocrystal, rice straw is low-cost and readily available, and is an exceptional candidate for a source of raw material.

Acknowledgments The authors gratefully acknowledge the use of EM000700 of MOST 110-2731-M-006-001 belonging to the Core Facility Center of National Cheng Kung University (NCKU).

Funding This work was supported by the Ministry of Science and Technology in Taiwan (MOST 106-2221-E-006-092-MY3 and MOST 109-2221-E-006-046).

Data availability Not applicable.

Code availability Not applicable.

\section{Declarations}

Conflict of interest The authors declare that they have no known competing financial interests or personal relationships that could have appeared to influence the work reported in this paper. The manuscript was approved by all authors for publication.

Ethics approval This article does not contain any studies with human participants or animals performed by any of the authors. 
Consent to participate Not applicable.

Consent for publication Not applicable.

\section{References}

Bao W, Fang Z, Wan J, Dai J, Zhu H, Han X (2014) Aqueous gating of Van Der Waals materials on bilayer nanopaper. ACS Nano 8:10606-10612

Boonstra A, Mutsaers C (1975) Adsorption of hydrogen peroxide on the surface of titanium dioxide. J Phys Chem 79:1940-1943

Chen X, Si C, Fatehi P (2018) Enhancement in biological treatment of pulping wastewater by fly ash. Chemosphere 210:1-9. https://doi.org/10.1016/j.chemosphere.2018.06. 160

Davidsdottir B (2013) Forest products and energy. In: Reference module in earth systems and environmental sciences

Derkacheva O, Sukhov D (2008) Investigation of lignins by FTIR spectroscopy. In: Macromolecular symposia, 2008, vol 1. Wiley Online Library, pp 61-68

Dizhbite T, Telysheva G, Jurkjane V, Viesturs U (2004) Characterization of the radical scavenging activity of ligninsnatural antioxidants. Biores Technol 95:309-317

Dungchai W, Chailapakul O, Henry CS (2011) A low-cost, simple, and rapid fabrication method for paper-based microfluidics using wax screen-printing. Analyst 136:77-82

French AD (2014) Idealized powder diffraction patterns for cellulose polymorphs. Cellulose 21:885-896

French AD, Santiago Cintrón M (2013) Cellulose polymorphy, crystallite size, and the Segal crystallinity index. Cellulose 20:583-588

Fujisaki Y, Koga H, Nakajima Y, Nakata M, Tsuji H, Yamamoto T, Kurita T, Nogi M, Shimidzu N (2014) Transparent nanopaper-based flexible organic thin-film transistor array. Adv Funct Mater 24:1657-1663

Gould JM (1985) Studies on the mechanism of alkaline peroxide delignification of agricultural residues. Biotechnol Bioengineer 27:225-231

Hinterstoisser B, Åkerholm M, Salmén L (2001) Effect of fiber orientation in dynamic FTIR study on native cellulose. Carbohydr Res 334:27-37

Hintz H, Lawal S (2018) Paper: pulping and bleaching. In: Reference module in materials science and materials engineering

Hirakawa T, Nosaka Y (2002) Properties of O2--and OH. formed in $\mathrm{TiO} 2$ aqueous suspensions by photocatalytic reaction and the influence of $\mathrm{H} 2 \mathrm{O} 2$ and some ions. Langmuir 18:3247-3254

Hirakawa T, Yawata K, Nosaka Y (2007) Photocatalytic reactivity for $\mathrm{O}_{2}-$ and $\mathrm{OH}$ radical formation in anatase and rutile $\mathrm{TiO}_{2}$ suspension as the effect of $\mathrm{H}_{2} \mathrm{O}_{2}$ addition. Appl Cataly A 325:105-111

Hon DNS, Chang ST (1984) Surface degradation of wood by ultraviolet light. J Polym Sci Polym Chem Ed 22:2227-2241
Iwamoto S, Kai W, Isogai A, Iwata T (2009) Elastic modulus of single cellulose microfibrils from tunicate measured by atomic force microscopy. Biomacromol 10:2571-2576

Jour P, Halldén K, Wackerberg E (2013) Environmental systems analysis of alternative bleaching sequences with focus on carbon footprint. In: Proceedings of the ABTCP, the 46th ABTCP international pulp and paper congress, October, 2013, pp 8-10

Kumar A, Negi YS, Choudhary V, Bhardwaj NK (2014) Characterization of cellulose nanocrystals produced by acid-hydrolysis from sugarcane bagasse as agro-waste. J Mater Phys Chem 2:1-8

Law K, Kokta B, Mao C (2001) Fibre morphology and sodasulphite pulping of switchgrass. Bioresour Technol 77:1-7

Lin N, Dufresne A (2014) Surface chemistry, morphological analysis and properties of cellulose nanocrystals with gradiented sulfation degrees. Nanoscale 6:5384-5393

Mariano M, El Kissi N, Dufresne A (2014) Cellulose nanocrystals and related nanocomposites: review of some properties and challenges. J Polym Sci Part B Polym Phys 52:791-806

Muhammad S, Rao TN (1957) Spectrophotometric determination of the dissociation constant of hydrogen peroxide. J Chem Soc (Resumed):1077-1078

Oluwasina OO, Lajide L, Owolabi B (2014) Microcrystalline cellulose from plant wastes through sodium hydroxideanthraquinone-ethanol pulping. BioResources 9:6166-6192

Park S, Baker JO, Himmel ME, Parilla PA, Johnson DK (2010) Cellulose crystallinity index: measurement techniques and their impact on interpreting cellulase performance. Biotechnol Biofuel 3:10

Pędziwiatr P (2018) Decomposition of hydrogen peroxide-kinetics and review of chosen catalysts. Acta Innovat 26:45-52

Pourreza N, Golmohammadi H, Naghdi T, Yousefi H (2015) Green in-situ synthesized silver nanoparticles embedded in bacterial cellulose nanopaper as a bionanocomposite plasmonic sensor. Biosens Bioelectr 74:353-359

Puls J, Janzon R, Saake B (2006) Comparative removal of hemicelluloses from paper pulps using nitren, cuen, $\mathrm{NaOH}$, and $\mathrm{KOH}$. Lenzinger Berichte 86:63-70

Shi S-C, Jiang S-Z (2020) Influence of graphene/copper hybrid nanoparticle additives on tribological properties of solid cellulose lubricants. Surf Coat Technol 389:125655. https://doi.org/10.1016/j.surfcoat.2020.125655

Shi S-C, Pek S-S (2019) Third-body and dissipation energy in green tribology film. Appl Sci 9:3787

Shi S-C, Peng Y-Q (2020) Preparation and tribological studies of stearic acid-modified biopolymer coating. Prog Organ Coat 138:105304

Shi S-C, Wu J-Y, Peng Y-Q (2018) Transfer layer formation in $\mathrm{MoS}_{2}$ /hydroxypropyl methylcellulose composite. Wear 408:208-213

Sugiyama J, Vuong R, Chanzy H (1991) Electron diffraction study on the two crystalline phases occurring in native cellulose from an algal cell wall. Macromolecules 24:4168-4175

Sun RC, Fang J, Tomkinson J (2000) Delignification of rye straw using hydrogen peroxide. Ind Crops Prod 12:71-83 
Sun R, Tomkinson J, Mao F, Sun X (2001) Physicochemical characterization of lignins from rice straw by hydrogen peroxide treatment. J Appl Polym Sci 79:719-732

Sun X, Li M, Ren S, Lei T, Lee SY, Lee S, Wu Q (2020) Zeolitic imidazolate framework-cellulose nanofiber hybrid membrane as Li-Ion battery separator: basic membrane property and battery performance. J Power Sources 454:227878

Tian L, Morrissey JJ, Kattumenu R, Gandra N, Kharasch ED, Singamaneni S (2012) Bioplasmonic paper as a platform for detection of kidney cancer biomarkers. Anal Chem 84:9928-9934

Trache D, Hazwan Hussin M, Mohamad Haafiz MK, Thakur VK (2017) Recent progress in cellulose nanocrystals: sources and production. Nanoscale 9(5):1763-1786. https://doi. org/10.1039/C6NR09494E

Wang J, Deng Y, Qian Y, Qiu X, Ren Y, Yang D (2016) Reduction of lignin color via one-step UV irradiation. Green Chem 18:695-699
Yabuuchi N, Kubota K, Dahbi M, Komaba S (2014) Research development on sodium-ion batteries. Chem Rev 114:11636-11682

Yang Q, Fukuzumi H, Saito T, Isogai A, Zhang L (2011) Transparent cellulose films with high gas barrier properties fabricated from aqueous alkali/urea solutions. Biomacromol 12:2766-2771

Yu G, Xie X, Pan L, Bao Z, Cui Y (2013) Hybrid nanostructured materials for high-performance electrochemical capacitors. Nano Energy 2:213-234

Zhu H, Luo W, Ciesielski PN, Fang Z, Zhu JY, Henriksson G, Himmel ME, Hu L (2016) Wood-derived materials for green electronics, biological devices, and energy applications. Chem Rev 116:9305-9374

Publisher's Note Springer Nature remains neutral with regard to jurisdictional claims in published maps and institutional affiliations. 